\title{
Correction of disordered oral immunity in children affected by dental caries with herbal immune modulator "Esberitox"
}

\author{
Olena Cherepyuk ${ }^{1}$, Yuriy Oktysyuk ${ }^{1}$, Alexandra Bazalytska ${ }^{1}$, Mykola Rozhko ${ }^{1}$ \\ 1 Ivano-Frankivsk National Medical University, Department of Pediatric Dentistry, Ivano - Frankivsk, Ukraine \\ Corresponding author: Yuriy Oktysyuk (oktysyuk@gmail.com)
}

Received 2 April 2019 • Accepted 3 February 2020 • Published 27 November 2020

Citation: Cherepyuk O, Oktysyuk Y, Bazalytska A, Rozhko M (2020) Correction of disordered oral immunity in children affected by dental caries with herbal immune modulator "Esberitox". Pharmacia 67(4): 347-350. https://doi.org/10.3897/pharmacia.67.e35069

\begin{abstract}
Dental caries is the most prevalent pathological condition in the child population of Ukraine. Despite the achievements of medical science, dental caries in children remains one of the most actual problems nowadays. Epidemiological investigations conducted in different regions of Ukraine demonstrate that $62 \%$ of children have decay and in many parts of the country the statistic is even higher up to $96.5 \%$ when the intensity of carious damage fluctuates between 3.2 to 7.2 teeth. This article reflects the results of the study regarding correction of disordered oral immunity indexes by immune modulator "Esberitox" in children affected by different caries activity. We have confirmed the high efficiency of the recommended scheme of caries prophylaxis that is proved by positive dynamic of oral immunological indexes observed 24 month after the beginning of the research. There was a certain rise of lysozyme by about $21.1 \%$ and s-IgA has increased by $28 \%$ in children from prophylactic groups in comparison with control groups.
\end{abstract}

\section{Keywords}

children, dental caries, lysozyme, oral liquid, secretory immunoglobulin A

\section{Introduction}

Dental caries still affects large numbers of children up to $98 \%$ according to some epidemiological findings and there is little improvement of this problem. The statistic varies worldwide from $1 \%$ to $70 \%$ and there is a difference in levels of decay between the communities. The investigation by Brown et al. (2000) suggested that by 2 to 6 years of age the child population in USA has experienced dental decay due to not efficient prophylaxis. Therefore, caries presents a big social and health problem in the world.

In Ukraine the statistic also illustrates the high level of caries intensity and prevalence. According to Denha et al. (2013) the prevalence of tooth decay among preschoolers is $48 \%$ by intensity $1.09-2.5$ teeth in the central regions of Ukraine, in the West Ukraine, on the other hand, the prevalence in this age group reaches up to $97 \%$ and intensity of the dental decay is 7.1 teeth.

The child's body is at the constant state of development and it has been established that caries and its complications might cause a massive influence on the maxillofacial system and health in general. The decay is also affected by detrimental environmental pesticides and other chemicals in products, water and soil. The role of eco-pathogenic risk is of vital importance in pediatric stomatology as any hazardous substances may be extremely harmful in any amount and doses to the child's well being. The statistic provided by Bezvushko (2010) show that worsening of specific and not specific defense factors and oral in particular lead to development of immune pathological 
conditions that complicate caries, not carious abnormalities and periodontal disorders.

The findings of Borovskyy and Leontyev (2001) suggested that cariogenic potential is related to the main factors such as microbial agent and quality of the hard dental tissues that determines processes of demineralization and remineralization. The level of immune-biological resistance of the body is considered as being of vital importance. Hilyaseva (2012) claimed that the state of local oral immunity defines the course of carious process as acute or systemic that was proved by many laboratory and clinical investigations.

According to Ovruckyy et al. (1991) the secretory immunoglobulin A(s-IgA), lysozyme and other defense factors provide antibacterial, antiviral and antitoxic mechanisms of oral liquid. The role of s-IgA is neutralization of viruses, bacterial exotoxins and enzymes; it inhibits adhesion of bacteria to epithelial cells and dental surfaces. The study of Atler (2007) show that bacteriostatic, bacteriolytic and bactericide characteristics of lysozyme are based on its ability to destroy peptidoglycans of the cell wall and finally lead to their lyses. The researches of (Chawda et al. 2011; Chereda et al. 2012; Haeri-Araghi et al. 2018) demonstrated very controversial findings about the content and the role of s-IgA in oral liquid of children resistant and sensitive to dental caries.

The article demonstrates the results gained by correction of oral immunity indexes in 12 year old children with different caries activity by administration of herbal immune modulator. The results showed that the rational usage of "Esberitox" increases s-Ig A and lysozyme in oral liquid of the main group comparing with the control group.

\section{Materials and methods}

We have investigated sixty-one 12 years old children affected by dental caries. The main group consisted of 30 children, the control group-of 31 children. Dental examination was performed according to methods recommended by WHO (2013). The caries activity was assessed by T. Vinogradova: compensated (DMF1-3); sub-compensated (DMF 4-6); de-compensated (DMF 7-9). Children from the main group were provided with caries treatment and oral hygiene. These children were prescribed the immune modulator "Esberitox" (manufactured by „Shaper \& Brummer GmbH \& Co. KG”, Germany; with a registration number: UA/11978/01/01). Each tablet contains $3.2 \mathrm{mg}$ of dry extract (4-9:1) of an offset: Baptisia tinctoria rhizome; Echinacea purpurea and Echinacea pallida roots; young shoots and leaves of Thuja occidentalis L.. The pharmacological agent should be taken by the following scheme: 3 tablets 3 times a day swallowed with plenty of water. The duration of the treatment was 14 days. The endogenic prophylaxis was repeated twice a year (autumn and spring) over 2 years for the children of the prophylactic group.
Children from the control group were introduced with oral hygiene and caries treatment.

The efficiency of the recommended treatment was assessed by content of lysozyme and s-IgA in oral liquid of children. Oral liquid was collected in the morning before breakfast by a sterile pipette from the cavity floor into a sterile container. To estimate lysozyme in oral liquid the day flush of agar Micrococcus lysodeicticus 1/15 M with phosphate buffer $\mathrm{pH} 6.2$ was prepared in advance. The obtained suspension of Micrococcus was standardized by photo-electro-calorimeter KFK-2 with a green light filter until the optical density of 0.66 . Defrosted oral liquid $0.1 \mathrm{ml}$ was poured into a test tube (diluted 4 times with $1 / 15 \mathrm{M}$ of phosphate buffer $\mathrm{pH} 6.2$ ) and $2.0 \mathrm{ml}$ of standardized suspension of Micrococcus. The phosphate buffer $0.5 \mathrm{ml} \mathrm{pH} 6.2$ 1/15 M and $2.0 \mathrm{ml}$ of suspension of Micrococcus were transferred into three control tubes. The tubes were incubated for 30 minutes at temperature $37^{\circ} \mathrm{C}$ and optical density was estimated using KFK-2 by the right drum with a green light filter. The amount of lysozyme was assessed by the special gauge tables measured in $\mathrm{mcg} / \mathrm{ml}$.

The study of oral humoral immunity was conducted by estimation of secretory immunoglobulin $\mathrm{A}(\mathrm{s}-\mathrm{Ig} \mathrm{A})$ in oral liquid using immune enzymatic analysis with the reagent kit „s-IgA - IFA-BEST” (ZAT „Vector Best, Russia”).

We followed the ethical standards when working with the examined children and obtained the written permission from both parents for collection and investigation of biological materials.

The data was processed with Statistica 10.0 and the obtained results were analyzed using the Student distribution law. The difference between the compared groups was considered as statistically proved if the obtained probability in$\operatorname{dex}(p)$ did not exceed the selected initial level $(\alpha=0.05)$ or was equal, therefore $\mathrm{p} \leq 0.05$ ) was used as significance level.

\section{Results}

There has been a steady rise of lysozyme in oral liquid by $11.52 \%$ from $(33.25 \pm 1.52)$ to $(37.5 \pm 1.67) \mathrm{mcg} / \mathrm{ml}$ in children of the main group diagnosed with compensated caries established 24 month after the recommended complex in contrast to initial data $(\mathrm{p}<0.05)($ Table 1$)$.

The positive changes of lysozyme have also been noticed in children diagnosed with sub-compensated caries 2 years after the treatment and have increased in 1.4 times comparing to initial data $(\mathrm{p}<0.05)$.

However, the most impressive results have been achieved in children with de-compensated caries when the amount of lysozyme has increased by $33.28 \%$ from $(19.31 \pm 2.34) \mathrm{mcg} / \mathrm{ml}$ to $(28.94 \pm 2.31) \mathrm{mcg} / \mathrm{ml}(\mathrm{p}<0.05)$ that was recorded 2 years after the recommended complex treatment.

In children of the control group, on the other hand, the indices of lysozyme did not differ from the initial data according to examination taken 2 years after the beginning of the research $(\mathrm{p}>0.05)$. 
Table 1. Indices of lysozyme and s-IgA in oral liquid of children before and after treatment $(\mathrm{M} \pm \mathrm{m})$.

\begin{tabular}{|c|c|c|c|c|}
\hline \multirow[t]{2}{*}{ Indexes } & \multicolumn{2}{|c|}{ Main group } & \multicolumn{2}{|c|}{ Control group } \\
\hline & $\begin{array}{c}\text { Before } \\
\text { treatment }\end{array}$ & $\begin{array}{c}\text { After 24 } \\
\text { month }\end{array}$ & $\begin{array}{c}\text { Before } \\
\text { treatment }\end{array}$ & $\begin{array}{c}\text { After 24 } \\
\text { month }\end{array}$ \\
\hline \multicolumn{5}{|c|}{ Compensated dental caries } \\
\hline Lysozyme, $\mathrm{mcg} / \mathrm{ml}$ & $33.25 \pm 1.52$ & $37.5 \pm 1.67$ & $32.64 \pm 1.47$ & $33.1 \pm 1.66$ \\
\hline S-IgA, g/l & $0.24 \pm 0.02$ & $0.28 \pm 0.02$ & $0.23 \pm 0.03$ & $0.24 \pm 0.02$ \\
\hline \multicolumn{5}{|c|}{ Sub-compensated dental caries } \\
\hline Lysozyme, $\mathrm{mcg} / \mathrm{ml}$ & $24.55 \pm 2.14$ & $33.1 \pm 2.31^{\star 0}$ & $24.38 \pm 2.16$ & $22.1 \pm 2.52$ \\
\hline S-IgA, g/l & $0.17 \pm 0.03$ & $0.25 \pm 0.02^{* 0}$ & $0.18 \pm 0.03$ & $0.17 \pm 0.03$ \\
\hline \multicolumn{5}{|c|}{ De-compensated dental caries } \\
\hline Lysozyme, $\mathrm{mcg} / \mathrm{ml}$ & $19.31 \pm 2.34$ & $28.94 \pm 2.31^{\star \circ}$ & $18.94 \pm 2.36$ & $17.39 \pm 2.22$ \\
\hline S-IgA, g/l & $0.13 \pm 0.03$ & $0.22 \pm 0.02^{* 0}$ & $0.14 \pm 0.03$ & $0.13 \pm 0.03$ \\
\hline
\end{tabular}

There is an evidence to summarize that there was a rise of $s-\operatorname{IgA}$ by $14.29 \%$ ( $p>0.05$ ) observed in children with compensated caries after the appointed treatment. Comparing the end and the beginning of the research we have recorded also an 1.47-fold increased amount of s-IgA $(\mathrm{p}<0.05)$ in children diagnosed with sub-compensated caries. The analysis of s-IgA in children with de-compensated caries shows a 1.7 -fold rise in the values from $(0.13 \pm 0.03)$ to $(0.22 \pm 0.02) \mathrm{g} / \mathrm{l}(\mathrm{p}<0.05)$. Concentration of $\mathrm{s}$-IgA has not experienced any changes in children from the control groups after 2 years $(p>0.05)$.

\section{Discussion}

The findings of the study (Chomenko et al. 2013; Smolyar and Barylyak 2013) reflected the link between the occurrence of many oral diseases and general and oral immunity. According to data provided by M.A. Havrylenko (2015) there are severe periodontal distractions and damages of the hard dental tissues in children with disability despite prescribed topical anti-inflammatory therapy and improvements of oral hygiene that is proved by a rise of white cells and a decrease of epithelial cells in the sedimentary part of oral liquid. Investigations of Atler (2007) illustrated that s-IgA is the main humoral factor that affects bacterial metabolism and regulates normal oral microflora. The deficiency of s-IgA can lead to disorders between the oral microflora and the macro organism. The s-IgA inhibits microbial adhesion to the hard dental tissues and as a result contributes to development of dental caries and periodontal disorders. According to Doifode and Damle (2011) dental caries is a consequence of sensibilization in local immune system to auto-anti-genes of enamel or products of their modification that evolve influenced by physical, chemical and bacterial factors. The findings by L. Chomenko (2012) suggest that the increase of s-IgA in children of early age is influenced by extended activity of cariogenic microflora. In contrast, in children with decayed smooth surfaces of primary teeth, the level of s-IgA is much lower that can be explained by high microbial overloading and exhaustion of this immune link upon immaturity of the secretory immunity. As can been seen from our investigation, concentration of s-IgA depended on the severity of carious process that also correlates with other surveys (Chawda et al. 2011; Doifode and Damle 2011; Chereda et al. 2012).

The oral enzyme lysozyme is one of the important factors that catalyzes the hydrolysis of 1,4-beta-linkages between the carbohydrate units in the polysacharide backbone in peptidoglycan. The results of the researches conducted by (Bezvushko 2010; Hilyaseva 2012) reported that another role of this enzyme is the stimulation of phagocyte activity of leucocytes and participation in tissue regeneration. The data provided by N. Smolyar (2013) indicate the enhanced spectrum of microbial association in dental plaque of children with de-compensated caries and decline of lysozyme in oral liquid. The other author B. Chereda (2012) suggests that there is a misbalance between the microbial load and local immunity reflected in changes of biofilm followed by shifting of the hydrogen index to the acid side and increases demineralization of the hard dental tissues. The obtained data regarding the reduction of lysozyme activity in case of caries progression is confirmed by other sources and can be used in the diagnosis of this disease (Lertsirivorakul et al. 2015; Lertsirivorakul et al. 2015).

\section{Conclusions}

The results gained 24 month after the appointed treatment suggest that in children from the main group with sub-compensated caries there was a certain 1.5-fold increase of lysozyme; in children with de-compensated caries this index has increased 1.7 times as compared to the initial statistical data and indices in the control group $(\mathrm{p}<0.05)$.

The amount of s-IgA has increased by $32 \% 2$ years after the recommended treatment in children with sub-compensated caries and there was a growth by $41 \%$ in children with de-compensated caries in comparison to the initial level $(\mathrm{p}<0.05)$.

There has been a marked progress in prevention of dental caries by administration of the herbal immune modulator in children with moderate and high caries activity and we definitely recommend it for endogenic prophylaxis.

\section{References}

Brown LJ, Wall TP, Lazar V (2000) Trends in untreated caries in primary teeth of children 2 to 10 years old. The Journal of the American Dental Association 131: 93-100. https://doi.org/10.14219/jada.archive.2000.0027
Denha OV, Ivanov VS, Reizvich OE (2013) Indexes of dental caries in children of Ukraine, Russia and Belorussia over the period 19902010. Innovation of stomatology 2: 30-36. 
Bezvushko EV (2010) Complex assessment of dental health and physical development of children in the regions with polluted environment, Fluoride and Iodine deficiency. The environment and health 1: 45-47.

Borovskyy EV, Leontyev VK (2001) Biology of oral cavity. Medical book, Moscow, 304 pp.

Hilyaseva VV (2012) Modern aspects of donosologic diagnosis of dental caries. Modern problems of science and education 5: 47-54.

Ovruckyy HD, Marchenko AI, Zelinskaya NA (1991) Immunology of dental caries. Health, Kyiv, 96 pp.

Atler AY (2007) Immunologia. WMUP, Wroclaw, 364 pp.

Chereda VV, Petrushanko TO, Loban HA, Mamontova TV (2012) Microbial colonization of oral cavity and level of s-IgA inpeople with different intensity of caries. Ukrainian stomatological almanach 4: 19-21.

Chawda JG, Chaduvula N, Patel HR, Jain SS, Lala AK (2011) Salivary S IgA and dental caries activity. Indian Pediatrics 48(17): 719-721. https://doi.org/10.1007/s13312-011-0113-y

Haeri-Araghi H, Zarabadipour M, Safarzadeh-Khosroshahi S, Mirzadeh M (2018) Evaluating the relationship between dental caries number and salivary level of $\operatorname{IgA}$ in adults. Journal of Clinical and Experimental Dentistry 10(1): e66-e69. https://doi.org/10.4317/ jced. 54271
WHO [World Health Organization] (2013) Oral health surveys: basic methods $-5^{\text {th }}$ edition. WHO, $135 \mathrm{pp}$.

Chomenko LO, Bychkova NH, Bidenko HB (2012) The level of s-IgA in oral liquid of children under 3 years old affected by caries. News of stomatology 1: 108-109.

Smolyar NI, Barylyak DY (2013) Microflora of dental plaque in children according to intensity of caries. Prophylactic and pediatric stomatology 2: 26-29.

Havrylenko MA (2015) Cytological investigation of precipitated part of saliva in children with disability. Modern pediatry 4: 132-134. https://doi.org/10.15574/SP.2015.68.132

Doifode D, Damle SG (2011) Comparison of salivary IgA levels in caries free and caries active children. International Journal of Clinical Dental Science 2(1): 10-14.

Moslemi M, Sattari M, Kooshki F, Fotuhi F, Modarresi N, Sadrabad ZK, Shadkar MS (2015) Relationship of Salivary Lactoferrin and Lysozyme Concentrations with Early Childhood Caries. Journal of Dental Research, Dental Clinics, Dental Prospects 9(2): 109-114. https://doi.org/10.15171/joddd.2015.022

Lertsirivorakul J, Petsongkram B, Chaiyarit P, Klaynongsruang S, Pitiphat W (2015) Salivary Lysozyme in Relation to Dental Caries among Thai Preschoolers. Journal of Clinical Pediatric Dentistry 39(4): 343-347. https://doi.org/10.17796/1053-4628-39.4.343 